\title{
Circuit
}

Musiques contemporaines

\section{Les auteurs}

Volume 20, numéro 1-2, 2010

La musique contemporaine d'hier à demain

URI : https://id.erudit.org/iderudit/039645ar

DOI : https://doi.org/10.7202/039645ar

Aller au sommaire du numéro

Éditeur(s)

Les Presses de l'Université de Montréal

ISSN

1183-1693 (imprimé)

1488-9692 (numérique)

Découvrir la revue

Citer ce document

(2010). Les auteurs. Circuit, 20(1-2), 129-129. https://doi.org/10.7202/039645ar

Ce document est protégé par la loi sur le droit d'auteur. L'utilisation des services d'Érudit (y compris la reproduction) est assujettie à sa politique d'utilisation que vous pouvez consulter en ligne.

https://apropos.erudit.org/fr/usagers/politique-dutilisation/ 


\section{Les auteurs}

\section{NICOLAS DONIN}

Nicolas Donin, musicologue, est chercheur à l'Ircam où il anime l'équipe Analyse des pratiques musicales (Ircam-CNRS). II est l'auteur de nombreux travaux sur la musique contemporaine, l'histoire des pratiques d'écoute et d'analyse musicale depuis la fin du xIx siècle, et l'analyse musicale d'interprétation. Plusieurs de ces recherches sont réalisées en collaboration, notamment avec Rémy Campos et avec Jacques Theureau. Il est membre du comité de rédaction de Circuit, musiques contemporaines depuis 2001.

\section{MICHEL DUCHESNEAU}

Professeur à la Faculté de musique de l'Université de Montréal, Michel Duchesneau a complété un doctorat en musicologie à l'Université Laval, puis il a poursuivi des recherches postdoctorales en France. Auteur de plusieurs articles et conférences sur la musique française de la première moitié du xx siècle, il a aussi publié un livre intitulé L'avant-garde musicale en France et ses sociétés de 1871 à 1939 (1997). Outre ses activités de musicologue, Michel Duchesneau s'intéresse à la gestion dans le domaine des arts et a entre autres occupé le poste de directeur général de la Société de musique contemporaine du Québec de 1997 à 2002. II enseigne aujourd'hui le cours de gestion de carrière à la Faculté de musique de l'Université de Montréal. Rédacteur en chef de la revue Circuit, musiques contemporaines entre 2000 et 2006, son intérêt pour l'étude des courants musicaux d'avant-garde l'a poussé à fonder en 2003 l'observatoire international de la création musicale (OICM), équipe de recherche interdisciplinaire qui se consacre à l'étude de la création musicale de la fin du XIXe siècle jusqu'à nos jours.

\section{JONATHAN GOLDMAN}

Rédacteur en chef de Circuit, Jonathan Goldman a complété des études de premier cycle en philosophie et en mathématiques à l'Université McGill, pour obtenir ensuite une maîtrise puis un doctorat en musicologie de l'Université de Montréal en 2006 sous la direction de Jean-Jacques Nattiez, consacré à la forme dans la pensée et les œuvres de Pierre Boulez. II est professeur adjoint de musicologie à l'Université de Victoria. Jonathan Goldman a signé la préface aux Leçons de musique (2005) de Pierre Boulez, et prépare actuellement un ouvrage qui sera publié par Cambridge University Press sur la musique et les écrits de ce compositeur.

\section{JEAN-JACQUES NATTIEZ}

Jean-Jacques Nattiez est professeur de musicologie à la Faculté de musique de I'Université de Montréal. II est considéré comme un pionnier de la sémiologie musicale, discipline à laquelle il a consacré divers ouvrages, notamment Musicologie générale et sémiologie (1987). Son recueil d'articles, Le combat de Chronos et d'Orphée (1993), a été traduit en anglais, italien et portugais. Cofondateur de la revue Circuit, il a publié l'édition, entreprise avec Sophie Galaise et Jonathan Goldman, de deux volumes d'écrits de Pierre Boulez, Regards sur autrui et Leçons de musique (2005). II est également le directeur général de Musiques. Une encyclopédie pour le XXI siècle, dont les cinq volumes sont parus chez Actes Sud. En 2008, Jean-Jacques Nattiez a publié Lévi-Strauss musicien, chez Actes Sud. 